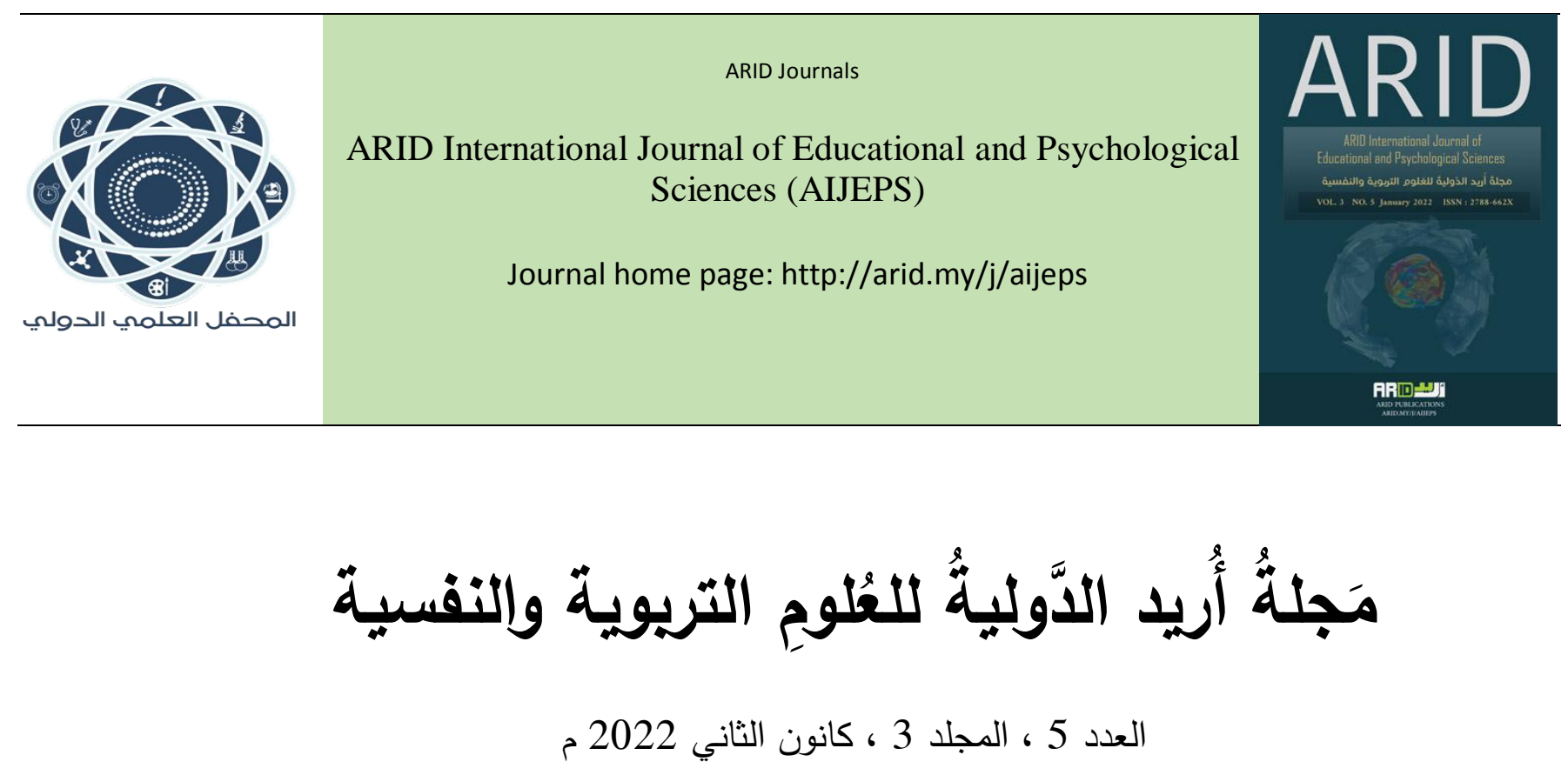

\title{
iPad's contributed to enhance inclusion of students with visual impairment in public schools
}

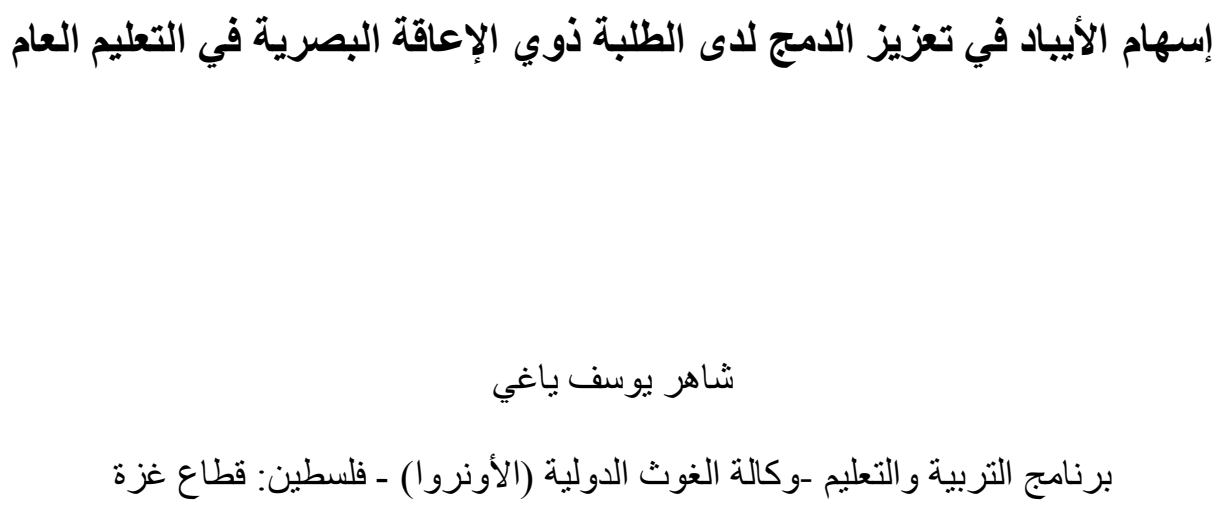




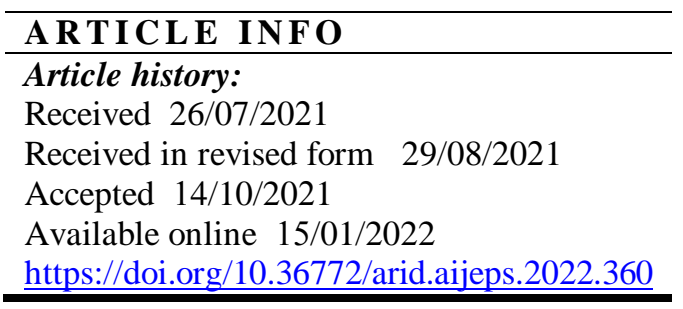

\begin{abstract}
This study aimed to identify the extent iPad's contributed to enhance inclusion of students with visual impairment (partially) in public schools. The study used the descriptive and analytical approach. The population consisted of (160) students who received iPad device within the "vision project" implemented at UNRWA schools in Gaza strip. The study used a questionnaire prepared and adapted by the researcher, to measure degree of iPad's contribution to inclusion in general and at three dimensions: academic, psychological, and behavioral. Results showed the level of iPad's contribution to enhance inclusion among students with visual impairment was high, with an average of 2.70 and a relative weight $90 \%$. Concerning the three dimensions, results showed the academic attained as average of 2.77 with relative weight $88.6 \%$, however in the second dimension (psychological) the mean was 2.98 with relative weight $99.3 \%$, lastly for the third dimension (behavioral), the mean was 2.67 with relative weight $89.0 \%$. This indicated high level of iPad's contribution to enhance inclusion of students with visual impairment at public schools specifically at UNRWA schools. The study recommended use iPads for best inclusive practices.
\end{abstract}

Key words: IPad - visual impairment - Inclusion in public schools. 


\section{الملخص}

هدفت هذه الدراسة إلى تعرف مدى إسهام الأيباد في تعزيز الدمج لدى الطلبة ذوي الإعاقة البصرية في التعليم العام. تكمن مشكلة

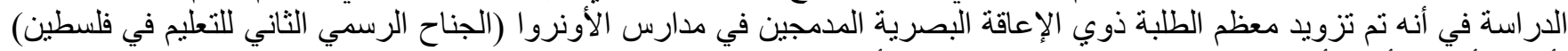

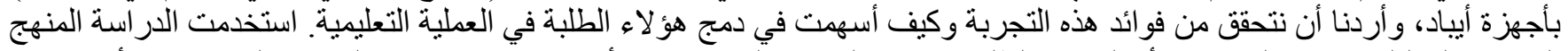

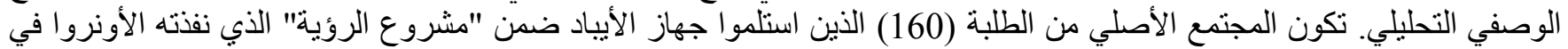

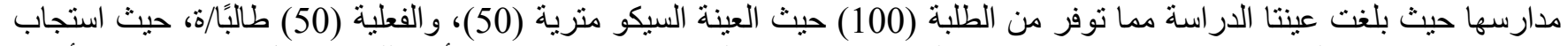

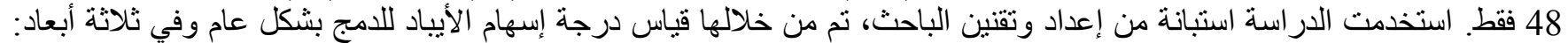

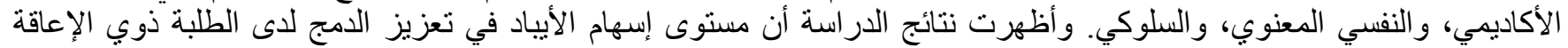

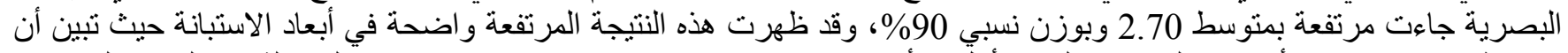

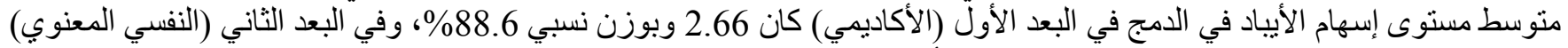

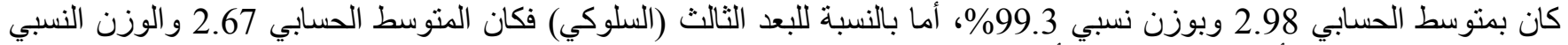

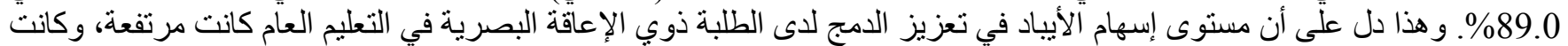

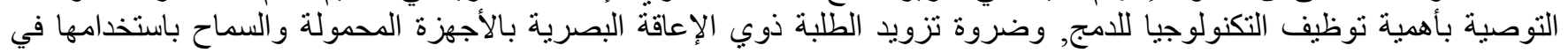




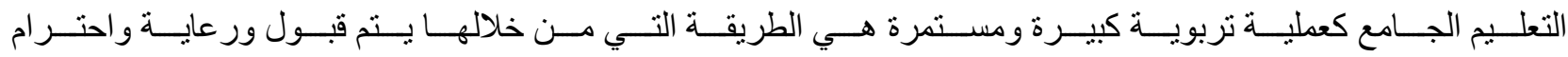

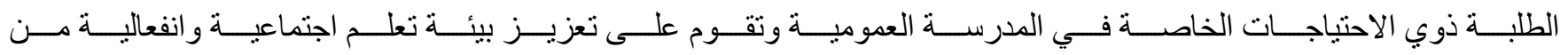

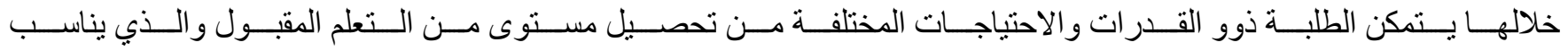

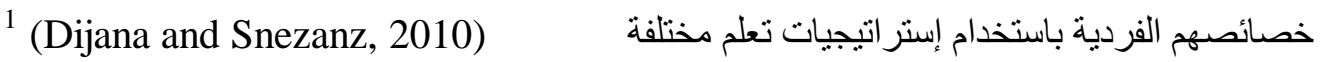
و الإستر اتيجيات المدرسية الجامعة هي التي تمكن الطلبة من الدمج الفاعل و الفعال في بيئة مدرسية آمنـة ومحفزة للتعلم تحترم الجميع وتكرس حقوق الإنسان وبالذات حقوق الأطفال، حيث كان يتم استبعاد هؤلاء الطلبة من المنظومـة التعليميـة بالكامل، و أصبح بعد عقود من الزمن فكرة الاهتمام بهم مقبولة ولكن بعيدًا عن النظام، حيث يقدم لهم خدمات تعليميـة في مر اكز أو مدارس خاصـة بهم بعيدة ونائية عن المدرسة العمومية. ولكن تطور المفهوم والممارسة بسبب التطور في مبادئ حقوق الإنسان وحقوق الطفل ومكافحة التمييز و إعطاء فرص متكافئة، مكًن دمج الطلبة (بشرط تأهيلهم) في النظام التعليمي ولكن يقدم لهم خدمات خاصـة بهم في المدرسـة مثل مر اكز المصادر أو المساندة, و هذا يسمى توحيد المسار Mainstreaming. أما التوجه الحديث وبعد العام 2000 وتبني اليونسكو التعليم للجميع و مبدأ No Child Left Behind أصبح التفكير و الممارسة في كيفية إدماج جميع الطلبة ذوي الاحتياجـات الخاصـة في النظام التعليمي العام ( ياغي 2019:1) . و ألزمت الأونروا2 نفسها من خلال إعلانها عما يُسمى بجملة الالتزام التي نصت على ما يلي: "تلتزم الأونروا بتقديم تعليم ذي جودة عالية يحترم حقوق الطفل ويقدر تنو عهم. وتهدف الأونروا إلى إز الـة جميع المعيقات التي تحول دون الحصول على فرص متكافئة للتعلم و المشاركة لتمكين جميع الأطفال من بلوغ قدر اتهم الكامنة بغض النظر عن النوع الاجتمـاعي، واختلاف القدرات أو الإعاقات، أو الحالة الاجتماعية/ الاقتصادية أو الاحتياجات الصحية، و النفسية/ الاجتماعية (الأونروا 2012:1). ولتوفير تعليم ذي جودة عالية كمتطلب لتطبيق منحى التعليم الجامع، أصبحت الأنظمة التعليمية توظف التكنولوجيا الرقمية في التعليم للطلبة بما فيهم الطلبة ذوي الإعاقة، ونخص بالذكر توظيف أجهزة الأيباد في تحسين العملية التعليمية وتجويدها باعتبار هـا سهلة الحمل وتمتلك مميزات وخيار ات هائلة. وقد قام التربويون بإجر اء دراسات حول إمكانية توظبف الأيباد في العملية التعليمية مثل: دراسـة حول تطوير تصنيف لاستخدامات الأيباد في المدارس، ودراسـة (Sabrina, 2012) التعليم، الاستخدام، والفائدة و التحديات، ودراسـة (Ruth, et, al. 2016) حول تقييم استخدام الأيبـاد كأداة تعليميـة، ودر اسـة قنيبي، (2019) حول تطوير نموذج لإدخال الحاسوب اللوحي في العملية التعلمية التعليمية، ودر اسة العنزي، (2018) واقع استخدام الأيباد في 
العملية التعليمية وسبل تحسينه. و هناك دراسات ارتبطت بعلاقة استخدام الأيباد بالتحصيل مثل: در اسـة السعايدة، (2015) حول استخدام الأيباد في التحصيل الدراسي، ودر اسة (Swicegood 2015) حول أثر الأيباد على تحصيل المهار ات و الاتجاهـات الحسـابية، ودر اسـة، (Habler, B., et, al. 2015) لمر اجعة الأدلة حول نتائج الطلبة باستخدام الأيباد. (Tantawi,2021). وأصبح الأيباد يستخدم لدعم تعلم واندماج الطلبة ذوي الإعاقات والحاجات التعليمية, ولذلك ظهر في الأثر العديد من الدراسـات التي تناولت توظيف الأيباد في تعليم الطلبة ذوي الإعاقات و الحاجات التعليمية المختلفة مثل: دراسـة (Quick, Nicole 2014) حول (Orhan, et, al., الأيباد و الإعاقات المختلفة، ودر اسة (O’Malley, et, .al., 2014) حول الأيباد وتعليم الطلبة ذوي التوحد ودر اسة) (2017 حول توظيف الأيباد لدعم تعلم ذوي الاحتياجات التعليمية، ودر اسة المولي، (2019) حول استخدام الأيباد في تعليم الطلبة ذوي الإعاقة الفكرية. أمـا بالنسـبة للدر اسـات التي ركزت على استخدامات الأيبـاد من قبل الطلبة ذوي الإعاقة البصـرية فكانت تركز على المواد الدر اسية مثل: در اسـة (Carole \& Rosenblum, 2019) فكانت تتعلق بحل المسـائل الرياضية، ودراسـة (Joan Hope, 2019) حول تدريب الطلبة ذوي الإعاقة البصرية للوصول للأجهزة اللوحية، وبحسب حدود علم الباحث فقد خلت الدراسـات التي تتعلق بالطلبة ذوي الإعاقة البصرية المدمجين في النظام العام، و هذا ما دفع الباحث بصفته منسقًا للتعليم الجامع في مدارس الأونروا القيام بهذه الدر اسـة لتعرف مدى إسهام الأيباد في دمج الطلبة ذوي الإعاقة البصرية "جزئيًا" في العملية التعليمية، مـع العلم أن الطلبة عينـة الدر اسـة, هم من استلموا أجهزة الأيباد ضمن مشروع يسمى مشروع الرؤيـة " vision project " وتم تزويدهم دون غير هم من الطلبة بـأجهزة أيباد بهدف دمجهم في العملية التعليمية. و عليه كان دائما هناك تساؤلّ عند قطاعات مختلفة في التعليم عن مستوى الفائدة التي استنفادها الطلبة عينة الدراسة على المستوى التعليمي، و المستوى النفسي، والمستوى السلوكي في الصف والمدرسة، ومدى إسهام جهاز الأيباد في تحقيق الدمج الفعلي لهم, و هذا ما ترنو إليـه هذه الدراسـة من خـلال الإجابـة عن سؤال الدراسـة، والخروج ببعض التوصيات التي قد تزيـ من مستوى التطبيق العملي للتعليم الجامع. 


\section{مشكلة الار اسة}

تكمن مشكلة الدر اسة في أن عدد الطلبة ذوي الإعاقة البصرية الجزئية المدمجين في مدارس الأونروا، وعددهم (166) طالبًَا وطالبـةً يعانون من الوصـول للمعرفة و المشـاركة الفاعلـة في العملية التعليميـة بسبب صسعوبة حمل الكتب المكبرة، وحـاجتهم لاستخدام طاولة متحركة (أي بعجلات ) للوصول للسبورة كي تصبح الرؤيسة أوضـح. وقد أظهرت بعض المقابلات التي قام بها معلمو التربيـة الخاصـة للطلبة وأولياء أمور هم أن و اقع الإعاقة لدى هؤلاء الطلبة انعكس بشكل سلبي على الجوانب التحصيلية، والنفسية من خجل ومفهوم متدنٍ عن الذات, وبالتالي العزلة وقلة المشاركة والاندماج الفعال. وللتغلب على هذه التحديات تم تزويد الطلبة ذوي الإعاقة البصرية بأجهزة أيباد وتم تحميل كل المواد المقررة في المنهاج الفلسطيني كل حسب مرحلته التعليمية، وتم تقديم الدعم اللوجستي والفني للطلبة داخل المدارس، ومع ذلك ظهرت مشكلة الدر اسة في غياب المعلومات البحثية عن فائدة هذا المشروع "مشـروع الرؤيـة لوصـول الطلبـة ذوي الإعاقة البصرية لتعليم جيد"، ومدى إسهام الأيباد في تحقيق الأهداف المرجوة منه، ولذلك كانت هذه الدراسة لتعرف مدى إسـهام الجهاز المستلم في تحقيق المساعدة الحقيقية للطلبة في الاندماج من الناحية التعليمية، والنفسية, و السلوكية، وتتلخص مشكلة الدر اسـة في السؤال الرئيس الآتي:

ما إسهام الأيباد في تعزيز الدمج لاى الطلبة ذوي الإعاقة البصرية في مدارس التعليم العام؟

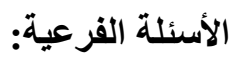
ويجيب عن السؤال الرئيس الأسئلة الفرعية الآتية: 1. ما مستوى إسهام الأيباد في تعزيز الدمج لدى الطلبة ذوي الإعاقة البصرية في مدارس الأونروا؟ 2. ما درجة إسهام الأيباد في تعزيز دمج الطلبة ذوي الإعاقة البصرية من الناحية التعليمية؟ 3. ما درجة إسهام الأيباد في تعزيز دمج الطلبة ذوي الإعاقة البصرية من الناحية النفسية؟ 4. ما درجة إسهام الأيباد في تعزيز دمج الطلبة ذوي الإعاقة البصرية من الناحية السلوكية؟ أهداف الدراسة 1. تعرف مدى إسهام جهاز الأيباد المستلم ضمن مشروع الرؤيـة في تعزيز الدمج الفعلي للطلبة ذوي الإعاقة البصرية المدمجين في مدارس الأونروا من وجهة نظر الطلبة أنفسهح. 2. التحقق من مستوى إسهام الأيباد في تعزيز دمج الطلبة ذوي الإعاقة البصرية من الناحية التعليمية الأكاديمية؟ 3. تحديد مدى إسهام الأيباد في تعزيز دمج الطلبة ذوي الإعاقة البصرية من الناحية النفسية المعنوية؟ 4. تعرف مستوى إسهام الأيباد في تعزيز دمج الطلبة ذوي الإعاقة البصرية من الناحية السلوكية في المشاركة الصفية والمدرسية؟ 
تكمن أهمية الدراسة في أنها قد تساعد في تحقيق الأمور التالية:

1. ركيز الدراسة على تعليم الطلبة ذوي الإعاقة البصرية المدمجين (المتواجدين) في النظام التعليمي العام تحديدًا مدارس الأنروا، وليس في المؤسسات أو المدارس الخاصة أو مر اكز الدمج، وهذا ما قد يكسبها أهمية.

تفعيل الدر اسـة أهميـة توظيف التكنولوجيـا في العمليـة التعليميـة كـأدو ات تعليميـة مسـاعدة لا سيما للطلبـة ذوي الإعاقـة البصـرية

المدمجين في المدارس، وتبرز الدور الجديد للتكنولوجيا في سياق منحى التعليم الجامع الذي تتبناه الجهات الرسمية.

3. توفير الدر اسة مثالًا عمليًَا للممارسـات التعليميـة الجامعة4 المنشودة وطريقة قابلة للتطبيق في مجال دمج الطلبة ذوي الإعاقة في

الميدان التربوي، منسجمًا مع التوجهات الوطنية والدولية في التقام باتجاه تحقيق مبادئ العدالة و المساواة والمشاركة الفعالة للتلاميذ

ذوي الإعاقة.

إسـهام الدر اسـة في الإدمـاج الفعلي للطلبة ذوي الإعاقة البصـرية أثناء نواجدهم في مدارس النظـام العـام من خـلال تلبيـة حاجـاتهم للتعلم، لذا من المتوقع أن يكون أكثر المستفيدين من هذه الدراسـة هم الطلبة الفلسطينين الذين يعانون من إعاقات بصرية، ممـا قد يؤدي إلى إيجاد المواطن الفعال بغض النظر عن إعاقته.

اعتبار هذه الدر اسة من در اسات الأساس في المجتمع الفلسطيني التي تهتم بالممارسـات الجامعة بشكل عملي في المجتمع التعليمي

الفلسطيني، وتوفر أداة مقننة تسهم في إثراء المكتبة المعرفية.

التعريفات الإجرائية

جهاز الأيباد: هو جهاز لوحي صمم من قبل شركة أبل تم إصداره في أبريل عام 2010، ويعمل بنظام تشغيل (IOS) وتدعم شاثتته اللمس المتعددة ويقوم بتشغيل عدة أنواع من الوسائط, ويوجد أكثر من جيل له (الرويلي 2014). وينتمي الأيباد إلى مجموعة من الألواح الذكية التي يتم التفاعل معها عن طريق لمس شاثـة مصممة لتنفيذ العديد من المهام، وهو أحد الأجهزة الإلكترونيـة الصغيرة نسبيًا و المزودة بإمكانية الاتصال بالإنترنت وتضمن تطبيقات متعددة تفاعلية (المولي2019). ويمكن تعريف الأيباد إجرائيًا: هو جهاز حاسوب لوحي محمول حجمه أصغر وأخف من الحاسب المحمول (اللاب توب) وأكبر من الهاتف الذكي، و هو شاثة سهلة الحمل تعمل باللمس وبه تطبيقات متعددة مثل التسجيل الصـوتي والتصـوير والتكبير، ومحمل عليه كل المو اد الدر اسية التابعة للمناهج الفلسطينية للصفوف الخامس والسادس الابتدائي وصفوف المرحلة الإعداديـة السـابع و الثامن و التاسع ليتم استخدامه في الغرفة الصفية وللمذاكرة. 
يتمنل الدمج في التعليم من خلال ما ورد في سياسة الأونروا للتعليم الجامع، و هو "منحى يقوم على أساس حقوق الإنسان وخصوصًا الحق في التعليم، ويقدر التعلبم الجامع التنوع لجميع الطلبة، ويعدل على تلبية /حتياجاتهم، مع التركيز بشكل خاص على الأطفال العرضـة للإقصاء والتهمبش، ويتطلب التعليم الجامع تحسين النظام التعليهي ليصبح أكثر استجابة لكافة /حتياجات الطلبة" (الأونروا، سياسـة التعليم الجامع، 2012:1).

تعزيز الامجج

و هو مقدار الزيادة في تلبية حاجات الطلبة ذوي الإعاقة البصرية كما تظهره نتائج الاستبانة أداة الدر اسة.

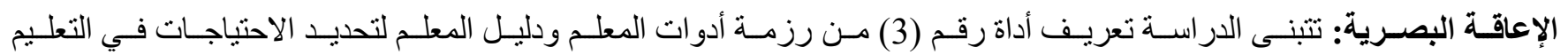
الجامع(2014:41): هم الطلبة الذين تم تشخيصهم طبيًا أو الذين لديهم ضـعف في البصر بشكل واضـح يؤثر على قدرتهم على الرؤيسة بشكل جزئي أو كلي في واحدة من العينين أو كلتيهما مـع استخدام النظـارة الطبيـة إذا كان ارتداء النظـارة يحل المشكلة فلا تعد إعاقة بصرية. الطلبة ذوو الإعاقة البصرية: هم الطلبة ذوو الإعاقـة البصرية الجزئية (الذين لديهم قصور في الرؤيـة حتى بعد استخدامهم للنظـارة الطبية) المسجلون رسميًا في النظام التعليمي العام في مدارس الأونروا, الذين تم حصر هم وتحديدهم من قبل المعلمين باستخدامهم أداة رقم (3) من رزمة أدوات التعليم الجامع. حدود الدراسة الحد الموضوعي: تقتصر الدراسة على التحقق من درجة إسهام جهاز الأيباد (ضمن مشروع الرؤية) في نعزيز دمج الطلبة ذوي الإعاقة البصرية في العملية التعليمية في مدارس الأونروا. الحد البشري: تتناول هذه الدراسة الطلبة ذوي الإعاقة البصرية الجزئية الذين استلموا أجهزة أيباد "ضمن مشروع الرؤيـة الهادف إلى الوصول الجيد للتعليم "Vision project" في مدارس الأونرو اللصفوف الخامس، والساد،، والسابع، و الثامن، والتاسع. الحد الرماني: تم تطبيق أداة الدراسة خلال العام الدراسي 2018 -2019. الحد المكاني: تأخذ هذه الدر اسة مكانها حيث يتو اجد الطلبة ذوي الإعاقة البصرية في جميع مدارس الأونروا المنتشرة في قطاع غزة. منهج وإجـــــاءات الدراســـة اتبع الباحث الإجر اءات المنهجية وفق الترتيب الآتي: 
أولا: منهج الاراسة: استخدم الباحث في هذه الدراسة المنهج الوصفي التحليلي لتعرف مدى إسهام الأيباد في تعزيز الدمج لدى الطلبة ذوي الإعاقة البصرية في مدارس الأونروا، في دراسة ميدانية تطبيقية. ثانيًا: مجتمع الدراسة: تكون المجتمع الأصلي للدر اسة من 160 طالبًا وطالبة من ذوي الإعاقة البصرية جزئيًا، المدمجين في مدارس الأونروا، الذين استلموا جهاز الأيباد ضمن "مشروع الرؤية" الذي تم تنفيذه في مدارس وكالة الغوث الدولية (الأونروا). ثالثًا: عينة الدراسة تألفت العينة من عينتين: السيكومترية (50) طالبًا وطالبة و العينة الكلية (50) طالبًا وطالبة، حيث بلغت العينة الكلية أو الفعلية (48) وتم استثناء استمارتين لعدم صـلاحيتهما. ويظهر جدول رقم (1) توزيع أفر اد العينة بالنسبة للخصـائص الديموغر افية و السكانية.

جدول(1):توزيع أفراد العينة بالنسبة للخصائص الايموغرافية والسكانية

\begin{tabular}{|c|c|c|c|}
\hline النسبة \% & 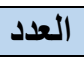 & التصنيف & \\
\hline$\% 8.3$ & 4 & مديريتي شمال غزة التعليمية & \multirow{6}{*}{ محافظات قطاع غزة } \\
\hline$\% 29.2$ & 14 & مديريات غزة التعليمية & \\
\hline$\% 20.8$ & 10 & مديريتي الوسطى التعليمية & \\
\hline$\% 22.9$ & 11 & مديريتي خانيونس التعليمية & \\
\hline$\% 18.8$ & 9 & مديريتي رفح التعليمية & \\
\hline 100.0 & 48 & المجموع & \\
\hline$\% 50$ & 24 & ذكر & \multirow{3}{*}{ نوع الجنس } \\
\hline$\% 50$ & 24 & أنتى & \\
\hline 100.0 & 48 & المجموع & \\
\hline$\% 4.2$ & 4 & الخامس & \multirow{6}{*}{ الصف } \\
\hline$\% 18.8$ & 9 & السادس & \\
\hline$\% 27.1$ & 13 & السابع & \\
\hline$\% 31.3$ & 15 & الثنامن & \\
\hline$\% 18.8$ & 9 & التاسع & \\
\hline 100.0 & 48 & المجموع & \\
\hline$\% 23$ & 13 & في المدرسة & \multirow{3}{*}{ مكان حفظ الجهاز } \\
\hline$\% 77$ & 35 & في البيت & \\
\hline 100.0 & 48 & المجموع & \\
\hline
\end{tabular}

تبين من خلال جدول (رقم 1) السابق ما يلي:

بالنسبة لتوزيع أفر اد العينة بالنسبة للمديريات التعليمية في قطاع غزة: كانت نسبة مدارس شمال قطاع غزة 8.3\%، ونسبة مدارس غزة التعليميـة \%29.2\%، بينما كانت نسبة مدارس الوسطى 20.8\%، أمـا مدارس خانيونس فقد كانت النسبة \%22.9\%، ونسبة مدارس رفح 18.8\%، كل ذللك من إجمالي التلاميذ ذوي الإعاقة البصرية المدمجين في مدارس التعليم العام بالأونروا. أما بالنسبة لتوزيع أفر اد العينة بالنسبة لنوع الجنس، شكل الذكور في العينة ما نسبته 50\%، ونسبة الإناث 50\%. أما بالنسبة لتوزيع أفراد العينة بالنسبة للصف، فقد تبين أن 4.2\% من الطلبة يدرسون في الصف الخامس، بينما 18.8\% في الصف السادس، في حين بلغت نسبة 
مكان حفظ جهاز الأيباد في المدرسة أو في البيت، فقد كانت نسبة الذين استلموا الجهاز ويأخذونـه معهم للبيت 77\%؛ بينما 23\% من الطلبة كانو ا يحتفظون به في المدرسة.

رابعًا: أداة الدراسة:

الاستبانة: تكونت الاستبانة من (18) فقرة موزعة على ثلاثة أبعاد تعبر عن الدمج: التعليمي، و النفسي، والسلوكي، وتم استخدام مدرج ثناثي لمقياس الاستبانة حيث (1) تعني بدرجة قليلة، و (2) بدرجة متوسطة، و (3) بدرجة كبيرة، ولذلك كانت الدرجة الكلية (389) درجة ومتوسط (3). الخصائص السيكو مترية للاستبانة، قام الباحث بحسـاب معاملات الصدق و الثبات والاتسـاق الداخلي للاستبانة على عينـة استطلاعية عددها (50) طالبًا/ةً. أولًا: صدق المقياس: قام الباحث بقياس الصدق من خلال الآتي: صدق المحكمين: عرض الباحث المقياس المقترح و المكون من (24) فقرة للتحكيم على مجموعة من المحكمين الخبر اء في مجالات التربية، والتربية الخاصة، و علم النفس، وتم حذف وتعديل و إعادة صياغة الفقرات التي عليها شبه إجماع، وقد بلـغ عدد فقرات المقياس بعد التحكيم (18) فقرة. ثنانيًا: ثبات المقياس: للتحقق من معاملات الثبات للمقياس تم حساب الثبات بطريقة ألفا كرو نباخ على النحو التالي: معاملات الثبات بطريقة ألفا ـ كرو نباخ: تم تطبيق الاستبانة على عينة استطلاعية قو امها (50) طالبًا وطالبة من ذوي الإعاقة البصرية المدمجين في مدارس الأونروا في قطاع غزة، وبعد تطبيق المقياس تم احتسـاب معامل ألفا كرونبـاخ لقياس الثبات، حيث وجد أن قيمـة معامل ألفا كرونباخ بلغت 0.914 للمقياس الكلي، و هذا دليل على أن المقياس يتمتع بمعامل ثبات مرتفع. ثالثًا: الاتساق الداخلي للاستبانة: تم التحقق من الاتساق الداخلي من خلال حساب معاملات الارتباط لكل بعد مع الدرجة الكلية للأداة، وبين كل فقرة من فقرات الاستبانة والدجة الكلية وذلك لمعرفة مدى ارتباط كل فقرة بالدرجة الكلية للبعد. وقد أظهرت النتائج أن جميع الأبعاد تتمتع بمعـاملات ارتبـاط قويـة ودالـة إحصـائيًا عند مستوى دلالـة (0.01)، جدول رقم (2) يظهر معاملات الارتبـاط بين أبعـاد المقياس والدرجة الكلية للمقياس، ويظهر جدول (3) معاملات الارتباط بين الفقرات و الدرجة الكلية للمقياس 


\begin{tabular}{|c|c|c|}
\hline مستوى الدلالة & معامل الارتباط & البعد \\
\hline$* * 0.001$ & 0.93 & التعليمي \\
\hline$* * 0.001$ & 0.85 & النفسي \\
\hline$* * 0.001$ & 0.89 & السلوكي \\
\hline
\end{tabular}

\section{ملحق (3)}

معاملات الارتباط بين عبارات كل بعد والارجة الكلية لكل بعد

\begin{tabular}{|c|c|c|}
\hline مستوى الدلالة & معامل ارتباط بيرسون & القفر ات \\
\hline \multicolumn{3}{|c|}{ البعد الأول: التعليمي } \\
\hline$* * 0.001$ & 0.62 & 1 \\
\hline$* * 0.001$ & 0.82 & 2 \\
\hline$* * 0.001$ & 0.73 & 3 \\
\hline$* * 0.001$ & 0.83 & 4 \\
\hline$* * 0.001$ & 0.82 & 5 \\
\hline$* * 0.001$ & 0.83 & 6 \\
\hline \multicolumn{3}{|c|}{ البعد الثاني: النفسي } \\
\hline$* * 0.001$ & 0.83 & 7 \\
\hline$* * 0.001$ & 0.82 & 8 \\
\hline$* * 0.001$ & 0.6 & 9 \\
\hline$* * 0.001$ & 0.74 & 10 \\
\hline$* * 0.001$ & 0.71 & 11 \\
\hline$* * 0.001$ & 0.47 & 12 \\
\hline \multicolumn{3}{|c|}{ البعد الثالث: السلوكي } \\
\hline$* * 0.001$ & 0.64 & 13 \\
\hline$* * 0.001$ & 0.77 & 14 \\
\hline$* * 0.001$ & 0.66 & 15 \\
\hline$* * 0.001$ & 0.87 & 16 \\
\hline$* * 0.001$ & 0.53 & 17 \\
\hline$* * 0.001$ & 0.61 & 18 \\
\hline
\end{tabular}

نتائج الاراسة وتفسيراتها إجابة السؤال الأول وينص على: "ما مستوى مساهمة الأيباد في تعزيز الدمج لاى الطلبة ذوي الإعاقة البصرية في مدارس الأونروا؟" وللإجابة على هذا السؤال تم حساب المتوسطات و الانحر افات المعيارية و الوزن النسبي لاستجابات الطلبة عينة الدراسة على الاستبانة، كما هو موضح في جدول رقم 
(4)، حيث تبين أن مستوى مساهمة الأيباد في تعزيز الدمج لاى الطلبة ذوي الإعاقة البصرية في مدارس الأونروا جاء مرتفعًا بمتوسط 2.70 وبوزن نسبي 90\%، وقد ظهرت هذه النتيجة في أبعاد الاستبانة حيث تبين أن منوسط مستوى مساهمة الأيباد في الدمج في البعد الأول (التعليمي) كان 2.66 وبوزن نسبي 88.6\%، وفي البعد الثاني (النفسي) كان بمتوسط الحسابي 2.98 وبوزن نسبي 99.3\%، أما بالنسبة للبعد الثالث (السلوكي) فكان المتوسط الحسابي 2.67 والوزن النسبي 89.0\%. و هذا يدلل على أن مستوى مسـاهمة الأيباد في تعزيز الدمج لدى الطلبة ذوي الإعاقة البصرية في مدارس الأونروا كان مرتفعًا. وبناء على آراء الخبراء تم اعتبار الفقرات التي تتو افر بوزن نسبي أقل من 55\% بأنها منخفضـة، ومن (55\% - 77\%) متوسطة ولكن أكثر من (77\%) تكون الاستجابات مرتفعة. ويمكن ترتيب الأبعاد تبعًا للأوزان النسبية كالآتي: البعد النفسي، ثم البعد السلوكي (في التفاعل المشاركة)، وأخيرًا البعد التعليمي مع العلم أن هذا الترتيب لا يضيف كثيرًا طالما أن جميع الأبعاد حصلت على أوزان نسبية مرتفعة. جاءت نتائج الدر اسة الحاليـة في السؤال الأول مرتفعة ومتو افقة مـع دراسـة العنزي (2018) التـي أظهرت أن تقييم استخدام الأيباد في العملية التعليمية من وجهة نظر المعلمين و المشرفين التربويين كان مرتفعًا، وتو افقت نتائج الدراسـة بـأن الأيباد كان مفيدًا للطلبة ذوي الإعاقة كما جـاء في در اسـة (Karsenti \& Fiever 2013)، ودر اسـة (O’Malley, et, .al., 2014) حول فائدة الأيباد للطلبة ذوي إعاقة التوحد. وتتو افق هذه النتيجة مع دراسة السبد وبـادلي (2016) حول مسـاهمة التكنولوجيـا المسـاعدة في دمج فئة المعاقين بصريًا. ويرى غربي (2019) أن الأيباد يصب في تعزيز مـا يمكن تسميته "التعلم الذكي لمدرسـة الألفيـة الثالثة". ويعتقد أن هناك دورًا مهـا للتكنولوجيا في مساعدة الطلبة ذوي الاحتياجات الخاصة للتغلب على التحديات التي تفرضـها الإعاقة على الوصـول للتعليم، وتسـهم أيضًا في نمو هم والوصول والمشاركة في الحياة اليومية وبذلك يتحقق الدمج الحقيقي.

جدول(4): المتوسطات الحسابية والانحر افات المعيارية والأوزان النسبية المقياس (ن=48)

\begin{tabular}{|c|c|c|c|c|c|c|}
\hline الترتيب & النسبـيـن & الالمعــراري & المستوسـي المتي & الكلية & الفقرات عـــد & 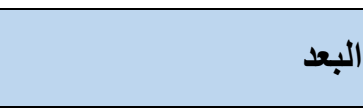 \\
\hline 3 & 88.6 & 440. & 62.6 & 127 & 6 & التعليمي \\
\hline 1 & 99.3 & 0.33 & 2.98 & 134 & 6 & النفسي \\
\hline 2 & 89.0 & 0.45 & 2.67 & 128 & 6 & السلوك الصفي والمدرسي \\
\hline-- & $\% 90$ & 0.40 & 2.70 & 389 & 18 & رجة الكلية للمقياس \\
\hline
\end{tabular}




\section{إجابة السؤال الثاني وينص على:}

" ما مستوى مساهمة الأيباد في تعزيز دمج الطلبة ذوي الإعاقة البصرية من الناحية التعليمية؟" وللإجابة على هذا السؤال تم حساب المتوسطات و الانحر افات المعيارية و الوزن النسبي لاستجابات الطلبة على الاستبانة، واتضح من خلال جدول رقم (5)، أن جميع فقرات البعد الأول كانت مرتفعة على النحو التالي: سهل من قدرتهم على التعلم بمتوسط حسابي 2.81 ووزن نسبي 83.6\% و سـاهم في رفع مستوى التحصيل لديهح بمتوسط حسـبي 2.79 ووزن نسبي 93\%، وحسن من مستوى القراءة و الكتابـة بمتوسط 2.67 ووزن نسبي 89\%، وسهل عملية التدريس للمعلم بمتوسط 2.67 ووزن نسبي 89\%، وز اد من قدر ات ومعارف الطلبة بمتوسط 2.58، ووزن نسبي

86\% وأخيرًا حسن من المستوى الأكاديمي و المعرفي لدى الطلبة ذوي الإعاقة البصرية بمتوسط حسابي 2.45 ووزن نسبي 81.6\%. يرى الباحث أن معظم الدراسات التي تتعلق بالأيباد داخل المدارس كانت تتعلق بالتحصبل وتحسن نتاجات التعلم وهي بذلك تعزز الإجابـة على السؤال الثاني في هذه الدر اسة. تؤكد النتائج مـا جاء بـه (Orhan et, al., 2016) أن أجهزة الأيباد كانت مفيدة لتعلم الرياضيات، و العلوم كما جاء في دراسة السعايدة (2017) ، ودر اسـة (Swicegood, 2015) ، حول فائدة الأيباد لتنفيذ أهداف المنهاج و المعلمين، وتنسجم نتائج الدر اسة مع ما جاءت به دراسـة (Ruth, et, al. 2016) أن فوائد استخدام الأيباد في التعليم يفوق التحديات. أمـا بالنسبة للطلبة ذوي الإعاقة البصرية فقد انسمت الدراسة مـع نتائج دراسـة (Carole \& Rosenblum, 2019) التي أظهرت أن الأيباد سـاهم في مساعدة الطلبة ذوي الإعاقة البصرية في حل عدد أكبر من المسائل الحسابية من غير هم الذين استخدمو ا وسائل أخرى. إجابة السؤال الثالث وينص على: "ما مستوى مساهمة الأيباد في تعزيز دمج الطلبة ذوي الإعاقة البصرية من الناحية النفسية؟" وللإجابة على هذا السؤال تم حساب المتوسطات و الانحر افات المعيارية و الوزن النسبي لاستجابات الطلبة على الاستبانة، واتضح من خلال جدول رقم (5)، أن جميع فقرات البعد الثاني كانت مرتفعة وتم ترتيبها على النحو التالي: أظهر هم بصورة إيجابية بمتوسط حسابي 2.92 ووزن نسبي 97.3\% وزاد من دافعيتهم للتعلم بمتوسط حسـبي 2.88 ووزن نسبي 96\%، وأر احهم من استخدام الكتب المكبرة بمتوسط حسـبي 2.85 ووزن نسبي 95\%، ورفع من مستوى ثقتهم بأنفسهم بمتوسط حسابي 2.75 ووزن نسبي 91.6\%، وجعلهم أكثر سعادةً ورضا بمتوسط حسابي 2.73، ووزن نسبي 91\%، وأخير ا أر احهم من استخدام الكرسي المتنقل (للوصول للسبورة) بمنوسط حسابي 2.67 ووزن نسبي 89\%. تنسجم الدر اسة الحالية مع نتائج در اسـة (Carole \& Rosenblum, 2019) حيث أن دافعيـة الطلبة ذوي الإعاقة البصرية الذين استخدموا الأيبـاد كانت مرتفعـة أكثر من الطلبـة الذين استخدموا أوراق العمل الورقيـة. و أعطت أجهزة الأيباد للطفل فرصًا متز ايدة للاستقلال وأثرت بشكل إيجابي على سلوك الطفل وتقرير المصير (Rodríguez, Strnadová, and Cumming, 2013). ويرى الباحث أن العديد من الدراسات التي عالجت تأثير الأيباد على الجانب النفسي اقتصرت على الجوانب النمائية للأطفال كمـا 
ظهر في در اسـة عثــان (2019) وجريـة الجارديـان (2015)، و غابـت أو قلت الدر اسـات التـي اهتمت بالجانب النفسي بحسب علم الباحث، للطلبة الذين يستخدون الأيباد في المدارس وتفسير ذلك قد يعود الى الجانب الثقافي أو الاجتماعي حيث أن معظم الطلبة في مدارس فلسطين، لا يستخدمون الأجهزة المحمولة في المدارس و لا يوجد للعديد منهم أجهزة في البيوت مما أعطى ميزة معنوية للطلبة أن يكون معهم أيباد و هذا يفسر لمـاذا كانت الناحيـة النفسية مرتفعة في هذه الدر اسـة من وجهة نظر الباحث، حيث يوجد غياب أو ضعف للتعليم الإلكتروني في العديد من الدول العربية كما أكد عليه صو الحية (2019).

\section{إجابة السؤال الرابع وينص على:}

"ما مستوى مساهمة الأيباد في تعزيز دمج الطلبة ذوي الإعاقة البصرية من الناحية السلوكية؟" وللإجابة على هذا السؤال تم حساب المتوسطات و الانحر افات المعيارية و الوزن النسبي لاستجابات الطلبة على الاستبانة، واتضح كما في جدول رقم (5)، أن جميع فقرات البعد الرابع كانت مرتفعة على النحو التالي: زاد من اندماجهم في العملية التعليمية بمتوسط حسابي 2.77، وبوزن نسبي 92.3\%، وزاد من وصولهم للمعرفة بمتوسط حسابي 2.77، وبوزن نسبي 92.3\%؛ وحسن من مهار اتهم في استخدام التكنولوجيا بمنوسط حسابي 2.77، وبوزن نسبي 92.3\%، وز اد من تفاعلهم في الغرفة الصفية بمنوسط حسابي 2.69 ووزن نسبي 89.6\% ورفع مسنوى المشاركة لديهم بمتوسط حسابي 2.38 ووزن نسبي 79.3\%، ورفع من مشاركتهم في الأنشطة اللاصفية (اللامنهجيـة) بمتوسط حسابي 2.67 ووزن نسبي 89\%. تو افقت نتائج الدر اسـة الحالية على فائدة الأيباد على المستوى السلوكي مع در اسـة (Karsenti \& Fievez 2013) حول الطلبة ذوي الإعاقة، ودر اسة (O’Malley, et, .al., 2014) حول الطلبة ذوي إعاقة التوحد. كما وانسجمت نتائج الدراسـة الحالية مـع مـا ذكرتـه ظهور كلمة واحدة تكررت كثيرًا في دراسات الأيباد و هي: "المشـاركة"، ببسـاطة يبدو أن إخخال الأيباد في الفصل الدر اسي يجعل الأطفال متحمسين ومركزين. وواصلت (Anya Kamenetz, 2013) أنه وفقًا لإحدى الدر اسـات التي كانت لتنميـة مهار ات الرياضيات، لكنها أنتـارت إلى زيـادة في إكمال المهام المستقلة كمـا يتضـح من انخفاض في السلوكيات غير المتوافقة ومستويات تحفيز المعلم. وبعبارة أخرى، لم يتعلم الطلاب بالضرورة أكثر ولكن السلوكيات غير المقبولة كانت بدرجة أقل، و استمروا في التركيز في المهمة(Anya Kamenetz, 2013) . ويرى الباحث أن المشاركة هي حجر الزاوية بالنسبة لدمج الطلبة ذوي الإعاقة حيث أن الطلبة ذوي الإعاقة إذا أعطوا الفرصة للمشاركة وتم تعزيز مشاركتهم فإن ذلك يرفع من ثقتهم بـالنفس ويدفعهم للبحث و المعرفة وأن مشاركتهم تسهم في زيادة اندماجهم في الأنشطة الصفية والنشاطات المدرسية. 
جدول(5): نتائج أسئلة الأبعاد الثلاثة : التعليمي، والنفسي، والسلوكي

\begin{tabular}{|c|c|c|c|}
\hline الانحر اف المعياري & الوزن النسبي & الحسابي & فقراتمة البعد الأول في الدمج \\
\hline 0.66 & $\% 81.6$ & 2.45 & 1 \\
\hline 0.50 & $\% 93$ & 2.79 & 2 \\
\hline 0.49 & $\% 93.6$ & 2.81 & 3 \\
\hline 0.63 & $\% 89$ & 2.67 & 4 \\
\hline 0.63 & $\% 89$ & 2.67 & 5 \\
\hline 0.64 & $\% 86$ & 2.58 & 6 \\
\hline الانحراف المعياري & الوزن النسبي & 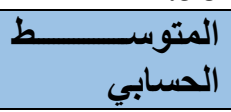 & فقراهمة الأيباد في التّمج \\
\hline 0.56 & $\% 91.6$ & 2.75 & 7 \\
\hline 0.44 & $\% 96$ & 2.88 & 8 \\
\hline 0.53 & $\% 91$ & 2.73 & 9 \\
\hline 0.40 & $\% 97.3$ & 2.92 & 10 \\
\hline 0.46 & $\% 95$ & 2.85 & 11 \\
\hline 0.51 & $\% 89$ & 2.67 & 12 \\
\hline الانحر اف المعياري & الوزن النسبي & 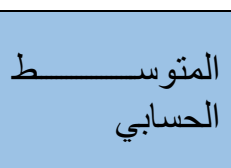 & 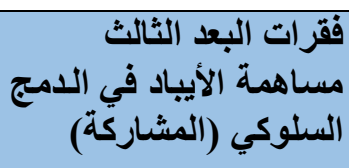 \\
\hline 0.51 & $\% 89.6$ & 2.69 & 13 \\
\hline 0.76 & $\% 79.3$ & 2.38 & 14 \\
\hline 0.66 & $\% 89$ & 2.67 & 15 \\
\hline 0.51 & $\% 92.3$ & 2.77 & 16 \\
\hline 0.55 & $\% 92.3$ & 2.77 & 17 \\
\hline 0.55 & $\% 92.3$ & 2.77 & 18 \\
\hline 0.55 & $\% 90$ & 2.70 & مجموع المحاور \\
\hline
\end{tabular}


1. تعميم تجربة توزيع أجهزة الحواسيب المحمولة مثل الأيباد أو أي أنواع أخرى وخصوصًا للطلبة ذوي الإعاقة البصرية

$$
\text { المدمجين في النظام التعليمي العام. }
$$

2. توزيع أجهزة الحواسيب المحمولة على طلبة لديهم إعاقات أخرى: مثل السمعية والتعليمية

\section{دراسات مقترحة}

1. در اسـة التحديات أو الصـوبات التـي تواجـه الطلبـة ذوي الإعاقـات البصرية في استخدام الأجهزة اللوحيـة المحمولـة في العملية التعليمية.

2. در اسة الفوائد و الصعوبات التي تو اجه أولياء أمور الطلبة ذوي الإعاقات البصرية في استخدام الأجهزة اللوحية المحمولة في العملية التعليمية.

3. در اسة الفو ائد والصعوبات التي تواجه المعلمين من استخدام الطلبة ذوي الإعاقات البصرية في استخدام الأجهزة اللوحية المحمولة في العملية التعليمية. 
الأونروا. (2012). سياسة التعليم الجامع. إدارة التربية و التعليم، عمان: المكتب الرئيسي.

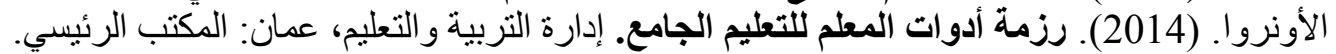

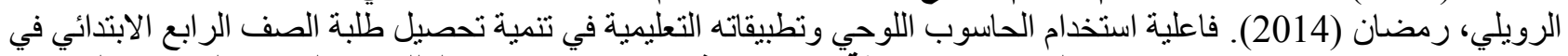

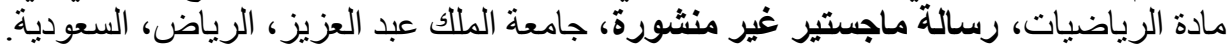

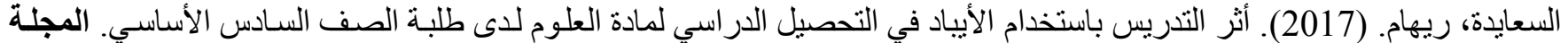

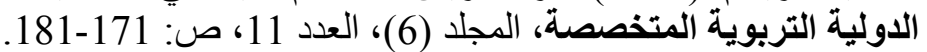

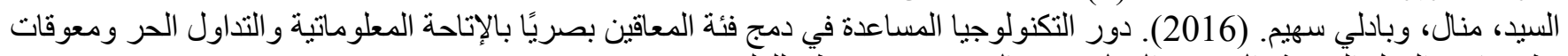
تطبيقها في الدول العربية. المؤتمر الدولي 22 بالكويت، موقع قطر للعلوم. Qscience Proceedings.

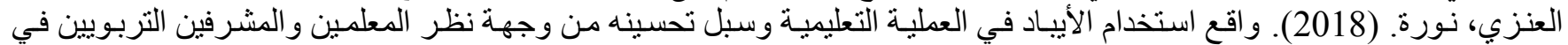

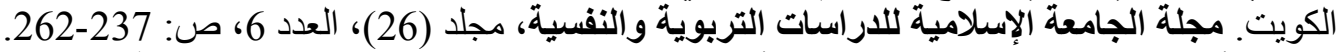

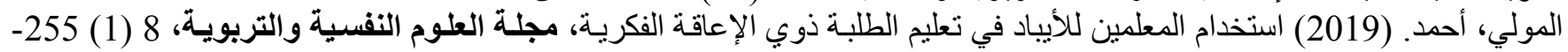
279 قنيبي، فاتتة. (276) (2019). تطوير نموذج مقتر ح لإدخال الحاسوب اللوحي في العملية التعلميـة التعليميـة. مجلة دراسـات، العلوم التربويـة، المجلد (46)، العدد 1 (2019.

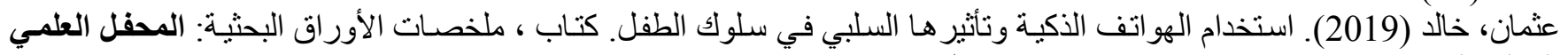

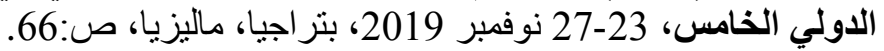

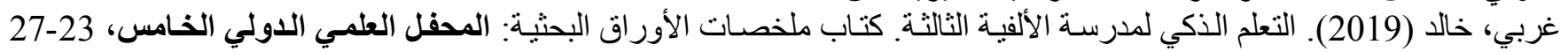

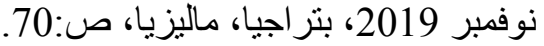

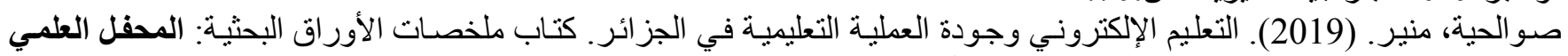

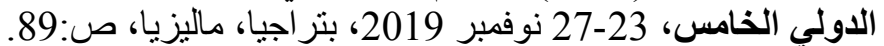

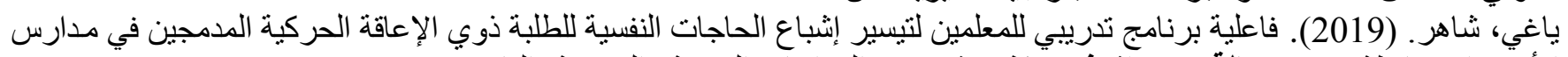

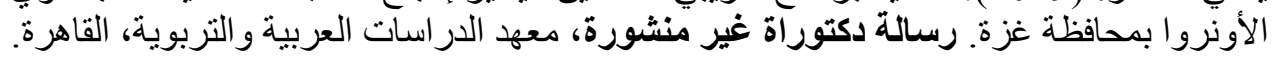

Anya Kamenetz, (2013) IPad in Special Ed: What does the research say? HTTPS://NPR.ORG/SECTIONS/ED/2014/06/13/321058641

Carole R. Beal and L. Penny Rosenblum. (2019). Evaluation of the Effectiveness of a Tablet Computer Application (App) in Helping Students with Visual Impairments Solve Mathematics Problems. Journal of Visual Impairment \& Blindness, pp 5-19

Dijana, H. \& Snezanz, J. (2010). Practical strategies to improve learning and achievements of pupils with special educational needs in elementary school. Procedia :Social and behavioral Sciences v2 p2911-2916.

Joan Hope. (2019). Educate blind, low-level blind students about accessibility features of the iPhones iPads. Disability Compliance for Higher Education. Wiley Periodicals, Inc., A Wiley Company, February 2018, DOI 10.1002/dhe.

Habler, B., Major. L. \& Hennessy S. (2015). Tablet use in schools: A critical review of the evidence for learning outcomes. Journal of Computer Assisted Learning, http://wileyonlinelibrary.com/journal/jcal.

Karsenti, T \& Fievez, A \& Collin, S \& Simard, S (2013). The iPad in Education: uses, benefits and challenges. A survey of 6057 students and 302 teachers in Quebec, Canada. Research gate, https://researchgate.net/publication/266672409

O’Malley, Patricia; Lewis, M.E.B; Donehower, Claire; Stone, David (2014). Effectiveness of using iPads to Increase Academic Task Completion by Students with Autism. Universal Journal of Educational Research 2(1): 90-97, 2014, DOI: 10.13189/ujer.2014.020111.

Orhan Simsek (2017). An exploration of teacher's use of iPads for students with learning support needs. Journal of Research in Special Educational Needs,

Research gate. DOI: 10.1111/1471-3802.12394. 
Quick, Nicole (2014). Using iPads to improve academic gains for students with disabilities. University of Rochester, Rochester, USA.

Rodríguez, Cathi; Strnadová, Iva and Cumming Therese (2013). Using iPads with Students with Disabilities: Lessons Learned from Students, Teachers, and Parents. Published by: Hammill Institute on Disabilities and SAGE,

http://isc.sagepub.com/content/49/4/244 exerted 10 Oct 2020 . exerted $8^{\text {th }}$ Oct, 2020

Ruth Diko Wario, Bonface Ngari Ireri and Lizette De Wet (2016). An evaluation of iPads as a learning tool in higher education within a rural catchment: a case study at a South African University, International Conferences ITS, ICEduTech and STE, ISBN: 978-989-8533-58-6.

Sabrina Huber. (2012) iPads in the Classroom - A Development of a Taxonomy for the Use of Tablets in Schools. Volume 2 of the series Internet-Technology and Society “, Books on Demand GmbH, Norderstedt.

Swicegood, Grant. (2015). An Investigation of the Impact of iPad Usage on Elementary Mathematical Skills and Attitudes. Graduate Student Theses, Dissertations, \& Professional Papers, University of Montana, https://scholarworks.umt.edu/etd/4591

The Guardian (2015) https://www.theguardian.com/technology/2015/feb/01/toddler-brains-researchsmartphones-damage-social-development

Tantawi, Sayed Mohammed Sayed (2021): The effectiveness of a training program using communicative theory in developing some concepts of Web 3 for educational technology specialists ,Arid International Journal of Educational and Psychological Sciences ,VOL.2 NO.3, January(pp. 6997).. 